\title{
KOMUNIKASI SENI INTRAPERSONAL DALAM PEMBELAJARAN MUSIK DENGAN RANGSANG AUDIO MENGUNAKAN METODE ZOLTAN KODALY
}

\author{
Andi Wijaya ${ }^{1}$ \\ 1. Program Studi Pendidikan Seni Tari STKIP PGRI Banjarmasin \\ andywijaya740@gmail.com (081364224848)
}

\begin{abstract}
ABSTRAK
Pelajaran yang disesuaikan antara materi seni musik dan seni tari karena tujuan seni budaya di sekolah umum bukanlah menjadi seniman, melainkan diharapkan mahasiswa mendapatkan pengalaman seni musik dan seni tari. Dalam proses komunikasi intrapersonal serta peningkatan kreativitas gerak tari yang dalam proses pembelajaran mata kuliah pengetahuan seni musik kepada mahasiswa dapat menumbuhkan kepekaan kepekaan audio yang telah dipelajarinya sebelum gerak tari dengan iringan musik yang terlebih dahulu mereka pelajari sebelumnya. Kepekaan rasa, pikir, dan kecintaan seni dapat mereka tumbuhkan serta kerjasama antara mata kuliah pengetahuan seni music dengan mahasiswa, dengan adanya rangsangan audio hasil bunyi recorder dan gerak hand signs tadi dapat dijadikan bahan untuk memotivasi gerak tari. Dengan demikian arah pendidikan seni sebenarnya pada perubahan sikap mahasiswa serta diharapkan mahasiswa dapat memperoleh pengetahuan dasar tentang kedua seni yang mereka pelajari antara seni musik dan seni tari penting bagi penyesuaian diri akan kehidupan masa depan. Perkembangan dari segi kreativitas ini harus diimbangi dengan peningkatan sarana bahan ajar yang menyangkut media di STKIP-PGRI Banjarmasin. Dalam seni budaya, gerak tari dan penggunaan rangsangan audio perlu dilakukan secara terus-menerus dan berkesinambungan karena tingkat keseringan yang terjadi pada mahasiswa akan mempengaruhi kepekaan mahasiswa dalam berproses gerak tari. Pelaksanaan kegiatan belajar mengajar seni bisa berjalan dengan baik, hal ini karena didukung dengan sikap mahasiswa yang sangat antusias dalam belajar, ketertiban dalam mengikuti pelajaran, selain itu juga faktor utama dari dosen yang bisa menerapkan metode yang tepat. Dengan adanya proses pembelajaran ini, diharapkan mampu meningkatkan kreativitas dan kepekaan.
\end{abstract}

Kata Kunci: Komunikasi Intrapersonal, Rangsang Audio Alat Musik Recorder, Metode Hand Signs

\section{A. Latar Belakang}

\section{PENDAHULUAN}

Pada hakikatnya ilmu adalah kesatuan tak terpisahkan dari tiga hal yang mendasar yang berhubungan satu sama lainnya, tiga hal itu yaitu proses suatu aktivitas (Warfield, 1976;42) yang dilaksanakan dengan metode (Kemeny, 1976;175), dalam rangka untuk menghasilkan kumpulan pengetahuan sistematis (Lachman,1969:13). Kumpulan pengetahuan sistematis sebagai hal ketiga pada dasarnya adalah produk atau hasil dari hal sebelumnya yaitu produk dari aktivitas 
dan metode yang dikerjakan oleh pelakunya

Dari pengetahuan di atas yang saya ketahui sebelumnya dalam membuat apa yang saya pahami, ketika saya bertanya kepada apa yang saya lihat atau semua orang yang pernah lakukan bahkan dialami setiap hari yaitu saat orang naik sepeda motor akan tetapi yang saya amati yaitu saat setiap orang dapat mengunakan semua bagian tubuh dia berkerja sendiri-sendiri dengan ruang tempat yaitu saat mengendarai motor itu sendiri dengan waktu yang berbeda dan bersamaan dapat menjadikan satu kesatuan dalam menjalankan motor tersebut sampai ketujuan misalnya saat motor itu berjalan mata kita dapat melirik ke spion dengan tangan kanan tetap pada posisi menaikan gas atau menurunkan gas motor bahkan tangan kiri kita dapat merokok di atas motor tersebut serta kaki kiri dapat menaikan auat menurunkan putaran roda 1,2,3 dan 4 dan kaki kanan kita dapat menekan rem dengan inilah yang menjadikan proses bertanya saya ke dalam diri saya yaitu bahwa fungsi kinerja otak dan organ lain dapat difungsikan sebagai mana mestinya ternyata proses saya ini dalam mata kuliah komunikasi seni bisa diartikan sebagai kontenks komunikasi intrapersonal dalam komunikasi seni dengan landasan beberapa pakar komunikasi seni menyetujui bahwa komunikasi inrapersonal atau intrapribadi merupakan jantung dari aktivitas komunikasi ( West and Turner, 2007:34), serta menurut mulyana (2002:72) komunikasi intrapersonal sebagai komunikasi dengan diri sendiri, baik yang disadari maupun yang tidak disadari.berarti sebelum adanya kreativitas di dahului dengan inrapersonal dalam menuju suatu kreativitas suatu bentuk langkah selanjutnya. Oleh karena itu pada kesempatan ini saya bahwa setelah proses komunikasi intrapersonal sebagai landasan disiplin ilmu sekaligus juga merupakan disiplin seni keduanya baik ilmu maupun disiplin ilmu seni memiliki keterkaitan dan kandungan elemen berupa aktivitas yang harus ditentukan .

Dan setelah itu saya menentukan proses pemikiran intrapersonal di atas tadi saya berpikir munkin ini dapat dilakukan dalam bermain musik dengan memfungsikan kesemua organ tubuh manusia hanya beda objeknya saja yang digantikan oleh ilmu dalam bermusik, dari landasan komunikasi intrapersonal tadi saya meminjam materi ilmu bermusik yaitu satu alat musik recorder atau suling yang biasa dimainkan oleh anak SD atau SLTA, dua yaitu metode hand sings dengan gerakan tangan bermainkan dengan ketetapan pola gerakan tangan kanan untuk merasakan perbedaan tinggi rendah nada atau picth dalam satu octave yaitu $1,2,3,4,5,6,7$, i atau 1 octave tangga nada mayor ,tiga pengucapan teknik solfa yaitu do, re, mi, fa, sol, la, si, do dengan suara atau vocal dan yang ke 4 saya memfungsikan telapak kaki sebagai ketukan dalam menyamakan terhadap tempo yang dimainkan dari semua materi diatas dengan landasan Mp3 backing track atau minus one atau istilahnya karaoke untuk menjadikan landasan iringan dari keselarasan materi dengan waktu yang telah ditentukan dengan konsep score musik yang saya dapat dari buku bermain suling atau recorder. (Effendy, 2003 : 58-59) menyatakan bahwa perangsang dari sisi internal dan ekternal akan dipilh pada tahap diskriminasi yang kemudian dikelompokan dan disandi balik ke lambang (symbol decoded) diubah menjadi lambang pikiran di dalam diri komunikator setelah penyandian balik menuju tahap ideasi (ideation) pemikiran perencanaan, pengorganisasian pikiran, kemudian dirumuskan pesannya dan direncanakan oleh komunikator intrapersonal. Tahap ini diikuti oleh inkubasi dimana titik ini melambangkan pikiran siap disandikan diubah menjadi kata atau 
kial (gesture) yang bermakna dan pada tahap transisi yang terakhir lambang kata kial disandi secara fisik dipancarkan dalam bentuk ucapan tulisan dan lainlainnya.

\section{B. Rumusan Masalah}

Kajian dari penelitian ini terutama berkaitan dengan masalah dari pemikiran komunikasi inrtrapersonal dalam bentuk wujud atas kreativitas sebuah pemikiran dan membatasi pada Program Studi Pendidikan Seni Tari STKIP PGRI Banjarmasin.

1. Bagaimana landasan pemikiran komunikasi intrapersonal seni pada perangkat materi di dalam kreativitas kolaborasi materi dalam bentuk ilustrasi gambar ?.

2. Bagaiman proses komunikasi intrapersonal bentuk prosesnya yang akan dilakukan oleh orang peraga ?.

3. Bagaimanakah pemikiran dari komunikasi intrapersonal dalam alur memainkan suatu peragaan dalam musik backing track?.

\section{Tujuan Penelitian}

Penelitian ini bertujuan untuk mengetahui:

1. Menjelaskan landasan pemikiran komunikasi intrapersonal seni pada perangkat materi di dalam kreativitas kolaborasi materi dalam bentuk ilustrasi gambar program studi Pendidikan Seni Tari STKIP PGRI Banjarmasin terhadap pelayanan Akademik STKIP PGRI Banjarmasin.

2. Menjelaskan tingkat kepuasan mahasiswa program studi Pendidikan Seni Tari STKIP PGRI Banjarmasin terhadap pelayanan Akademik STKIP PGRI Banjarmasin.

3. Menjelaskan arahan pemikiran dari komunikasi intrapersonal dalam alur memainkan suatu peragaan dalam musik backing track.

\section{Manfaat Penelitian}

Penelitian ini diharapkan akan bermanfaat, terutama :

1. Manfaat praktis dalam penelitian ini adalah sebagai informasi untuk masukan serta perbaikan proses pengelolaan pembelajaran pada Jurusan Pendidikan Seni Tari STKIP PGRI Banjarmasin. Dengan penelitian ini diharapkan akan diketahui persoalan serta hambatan yang dihadapi, sehingga dapat dijadikan sebagai titik pijak dan pemberi arah untuk perbaikan pengelolaan kualitas di masa yang akan datang.

2. Manfaat teoritis dari penelitian ini adalah memberikan sumbangsih terhadap perkembangan ilmu pendidikan, terutama yang berkaitan dengan pengelolaan (manajemen) pendidikan.

\section{METODE PENELITIAN}

\section{A. Rancangan Penelitian}

Sebuah strategi dapat berwujud rangsangan audio yang digunakan dalam mengatasi kendala dan hal-hal yang sulit diprediksi pada saat pembelajaran berlangsung, model pembelajaran ini dikemukakan oleh tokoh pendidikan musik abad 20 seperti Jaques Dalcroze dan Zoltan Kodaly yang akan dijelaskan pada gambar di bawah ini. 


\section{Dosen}

Menciptakan tantangan berupa permainan (games dan latihan

1. alat musik )
Mahasiswa

Mendengarkan dan merespon

2.

Menawarkan saran atau bantuan secara fisik,emosi atau suatu masalah -membuat grup untuk pemecahan masalah

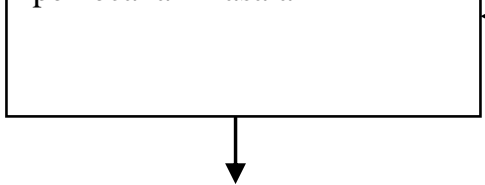

Menbantu siswa memahami secara umum apa yang akan di pelajari dan menawarkan solusi lain .
Mencoba berbagai kemungkinan gerak (move experimentaly)

enemukan cara untuk mengekspresikan solusi terhadap tantangan yang di berikan baik secara fisik,emosional maupun mental

3.

$$
\begin{aligned}
& \text { Mengubah musik atau } \\
& \text { permainan agar memperoleh } \\
& \text { pemahaman yang lebih dalam } \\
& \text { agar dapat membantu } \\
& \text { membuat solusi tambahan }
\end{aligned}
$$

4.

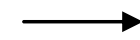

\section{B. Metode pembelajaran Zoltan Kodaly}

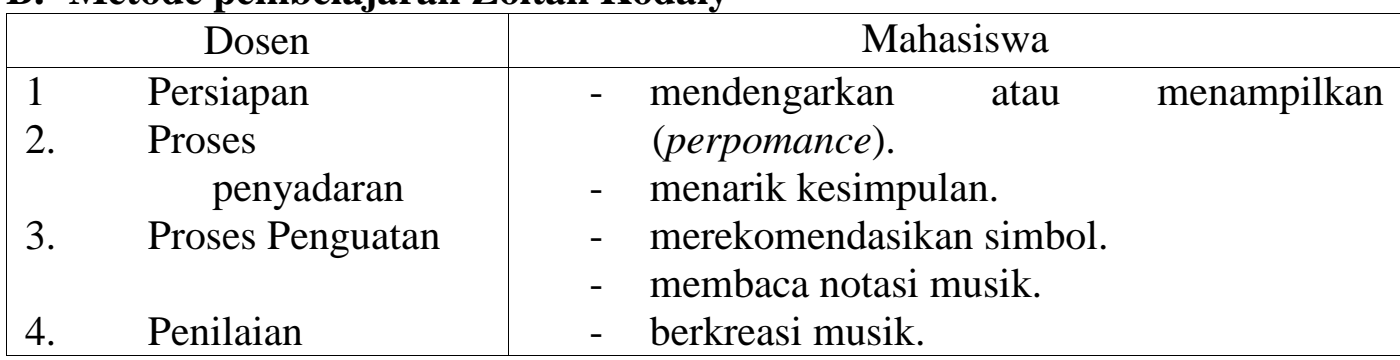




\section{Alat musik recorder}

Alat musik ini termasuk alat musik melodis diantaranya termasuk dalam kategori alat musik yang dimainkan secara aerophone yaitu dengan cara ditiup ( aerophone ) khusus alat musik recorder akan tetapi materi yang dimainkan sangat sederhana dengan mengenal letak nada solmisasi (do-re-mi-fa-sol-la-si-do) atau (c-d-e-f-g-a-b-c') atau wilayah 1 octave dalam inerval nada mayor pada alat tersebut.

Namun pada praktiknya mereka memainkan 4 nada yaitu sol-la-si-do dengan not huruf nya g-a-b-c1 tangg nada mayor (tertra II) serta do-re-mi-fa dengan not huruf nya (tertra II) atau dengan dikarenakan posisi yang dapat dimainkan sebelah tangan kiri dan kanan.

letak posisi jari di diagram nada 1 octave $\mathrm{C}=\mathrm{do}$

\section{Ujung / $\mathrm{U}$}

\begin{tabular}{|c|c|c|c|c|c|c|c|}
\hline $1 / \mathrm{do}$ & $2 / \mathrm{re}$ & $3 / \mathrm{mi}$ & $4 / \mathrm{fa}$ & 5/sol & 6/la & $7 / \mathrm{si}$ & $\mathrm{i} / \mathrm{do}$ \\
\hline $\mathrm{X}$ & $\mathrm{O}$ & $\mathrm{O}$ & $\mathrm{O}$ & $\mathrm{O}$ & $\mathrm{O}$ & $\mathrm{O}$ & $\mathrm{O}$ \\
\hline
\end{tabular}

\begin{tabular}{|r|r|r|r|r|r|r|r|}
\hline $\mathrm{X}$ & $\mathrm{X}$ & $\mathrm{O}$ & $\mathrm{O}$ & $\mathrm{O}$ & $\mathrm{O}$ & $\mathrm{O}$ & $\mathrm{O}$ \\
\hline $\mathrm{X}$ & $\mathrm{X}$ & $\mathrm{X}$ & $\mathrm{O}$ & $\mathrm{O}$ & $\mathrm{O}$ & $\mathrm{O}$ & $\mathrm{O}$ \\
\hline $\mathrm{X}$ & $\mathrm{X}$ & $\mathrm{X}$ & $\mathrm{X}$ & $\mathrm{O}$ & $\mathrm{O}$ & $\mathrm{O}$ & $\mathrm{O}$ \\
\hline $\mathrm{X}$ & $\mathrm{X}$ & $\mathrm{X}$ & $\mathrm{X}$ & $\mathrm{X}$ & $\mathrm{O}$ & $\mathrm{O}$ & $\mathrm{O}$ \\
\hline $\mathrm{X}$ & $\mathrm{X}$ & $\mathrm{X}$ & $\mathrm{X}$ & $\mathrm{X}$ & $\mathrm{X}$ & $\mathrm{O}$ & $\mathrm{X}$ \\
\hline $\mathrm{X}$ & $\mathrm{X}$ & $\mathrm{X}$ & $\mathrm{X}$ & $\mathrm{X}$ & $\mathrm{X}$ & $\mathrm{X}$ & $\mathrm{O}$ \\
\hline
\end{tabular}

\section{Lobang belakang / Lb}

\begin{tabular}{|r|r|r|r|r|r|r|r|}
\hline $\mathrm{X}$ & $\mathrm{X}$ & $\mathrm{X}$ & $\mathrm{X}$ & $\mathrm{X}$ & $\mathrm{X}$ & $\mathrm{X}$ & $\mathrm{X}$ \\
\hline $\mathrm{C}$ & $\mathrm{D}$ & $\mathrm{E}$ & & $\mathrm{F}$ & $\mathrm{G}$ & $\mathrm{A}$ & $\mathrm{B}$ \\
\hline
\end{tabular}

$\mathrm{C} 1$
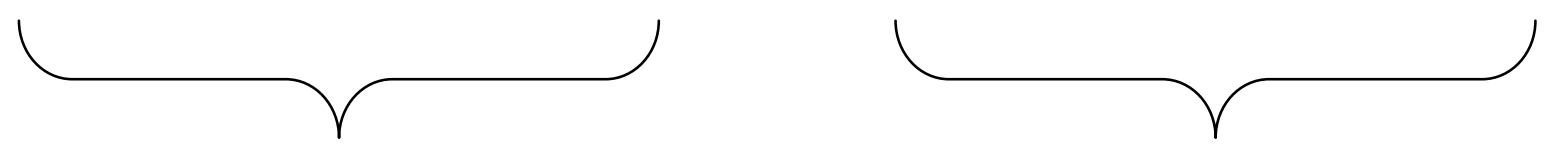

Tetra I

Tetra II

Ket:

$\mathrm{O}=$ dibuka dengan jari

$\mathrm{X}=$ ditutup dengan jari 


\section{Fingering Chat}
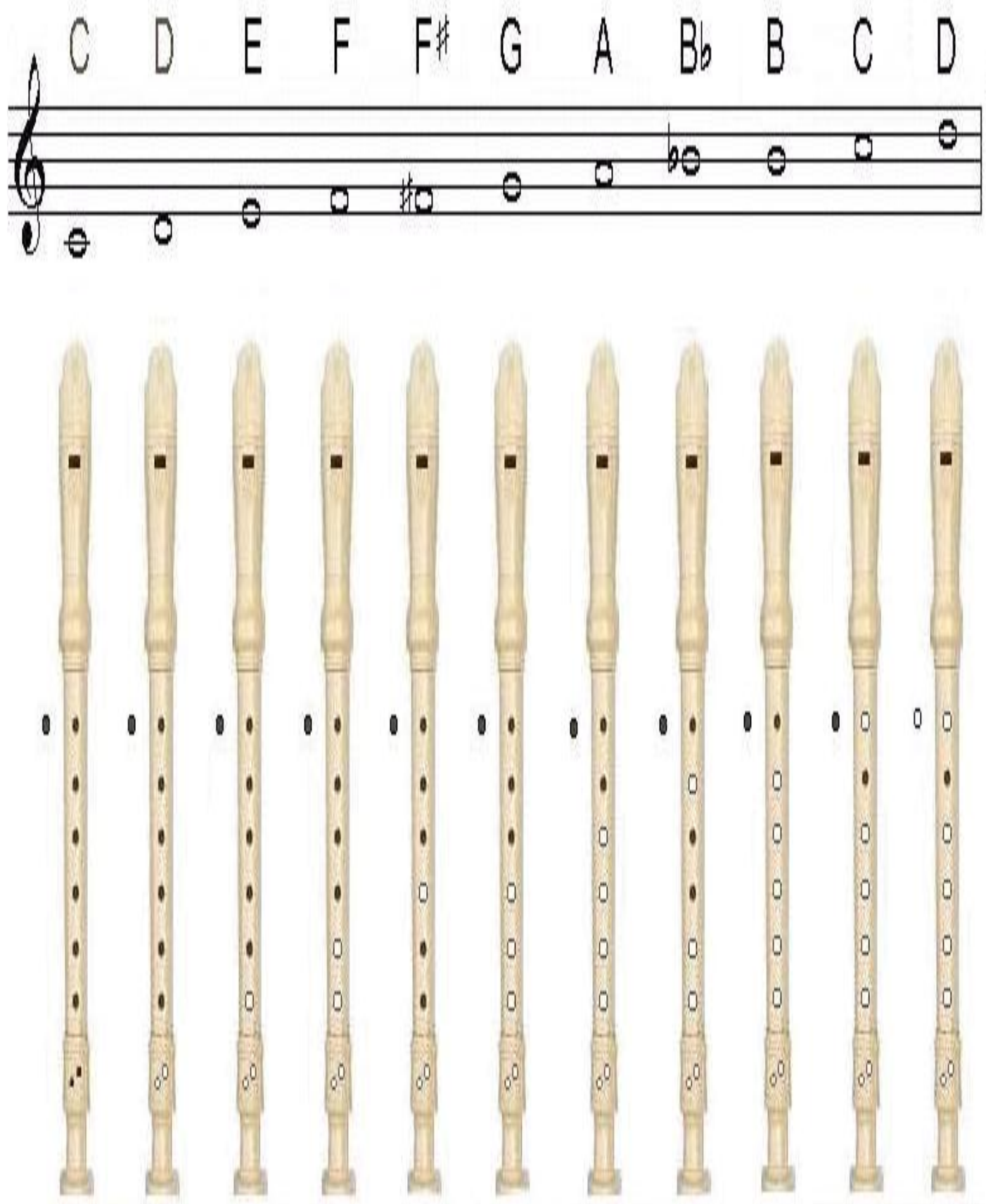

\section{Hand Signs}

Sistem pembelajaran tonik solfa merupakan media yang digunakan untuk membantu ingatan akan rasa dengan batuan pola gerakan tangan kemampuan tersebut akan dapat lebih cepat dicapai dan dapat bertahan lama dalam pikiran anak. Pola gerakan tangan dilakukan dalam wilayah batas pinggang dan di atas kepala (lihat lampiran gambar), saat melakukan aktivitas ini sebaiknya hanya 
melakukan dengan satu tangan yang lebih dominan saja (kiri atau kanan) di sarankan kanan.

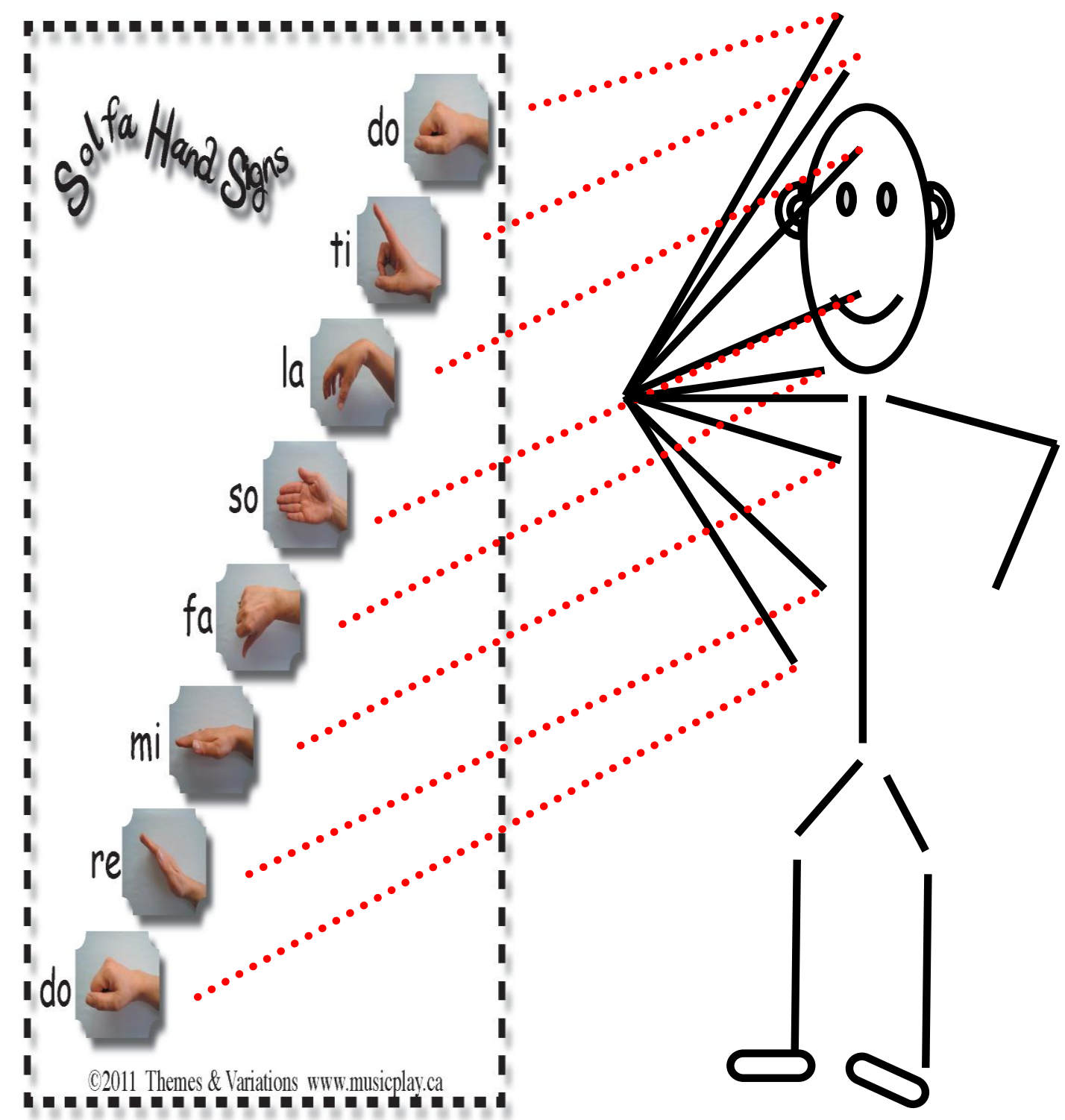

\section{Teknik Solmisasi}

Mengucapkan nada dengan mulut yang disesuaikan dengan not angka pada score yang dimainkan dengan mengucapkan do, re, mi, fa, sol, la, si, do. 


\section{Score materi}

\section{Bermain Recorder}
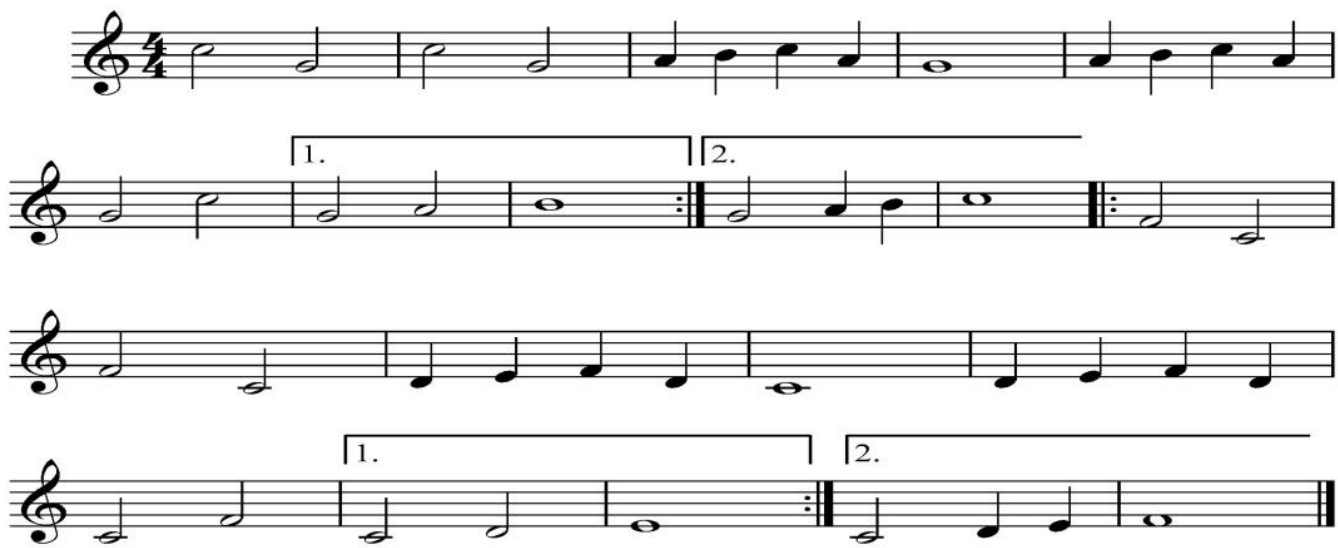

\section{HASIL DAN PEMBAHASAN}

Berdasarkan hasil penelitian didapatkan sebagai berikut, Dalam pemikiran yang melandasi komunikasi intra personal dalam mewujudkan dalam ide ke bentuk kreativitas saya menasumsikan seperti saat orang naik kendaraan akan tetapi disini saya sebelumnya membuat menuangkan hasil pemikiran intrapersonal dalam bentuk ilustrasi coretan dalam kertas saya pada saat itu seperti gambar di bawah ini.

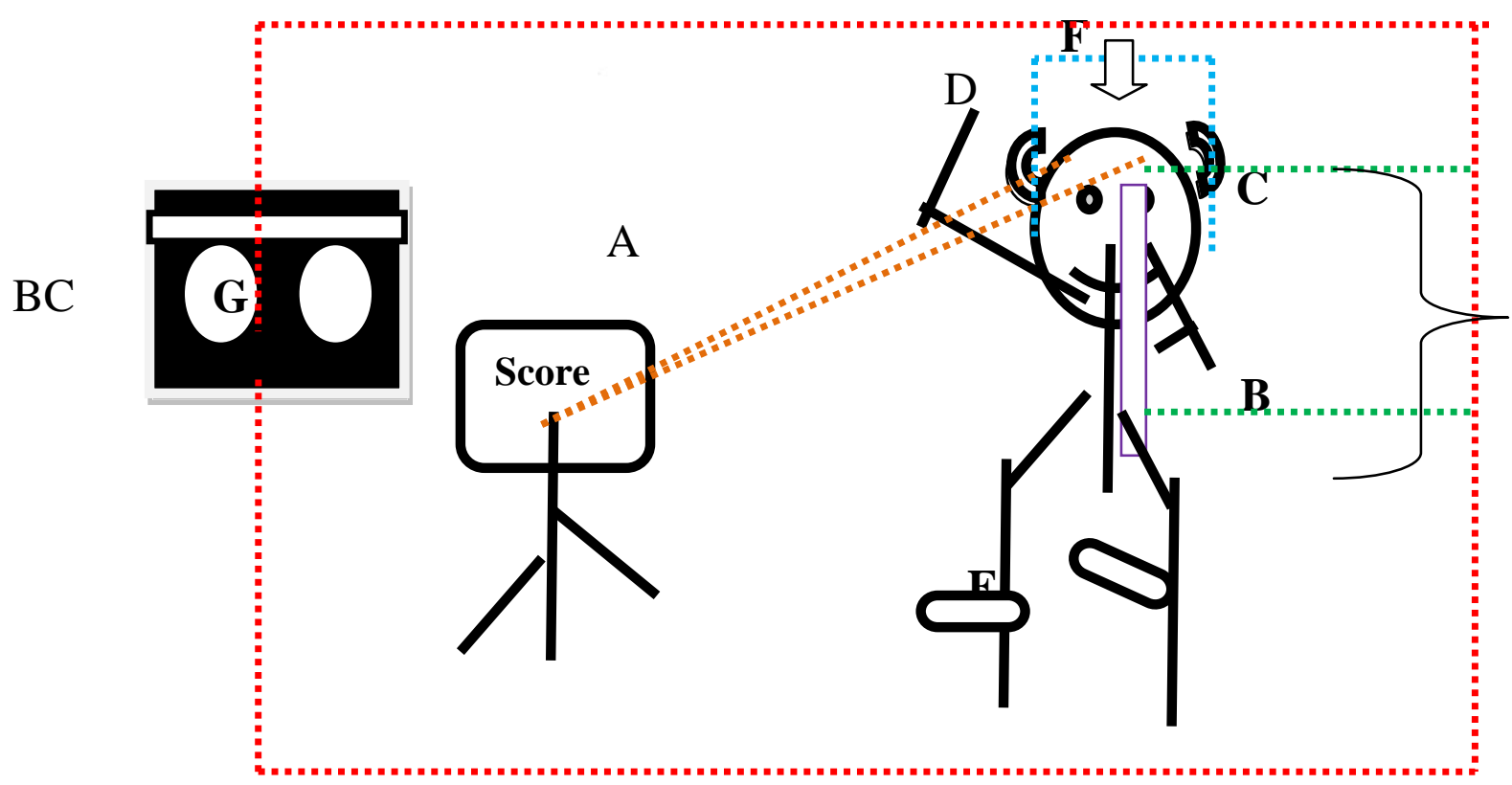

Materi praktik alat musik penguasaan recoder, hand sing, teknik solfa dalam 1 octave ( 1, 2, 3, 4, 5, 6, 7, i / c.d.e.f.g.a.b.c'/ do, re, mi, fa, sol, la, si, do ) dengan back sound / mp3 minus one yang telah di sediakan sebagai landasan 
penguasaan harga notasi balok score lagu bermain suling yang mana jumlah dalam praktiknya jumlah birama / bar score musik 16 yang dimainkan secara 3 kali putaran, dalam pembagian sesi di bawah ini :

- Di sesi putaran I memainkan alat musik recorder di tangan kiri dengan range nada 5, 6, 7, i / sol, la, si, do' (tetra II) atau kita sebut dengan Form A / bagian A dan tangan kanan memainkan posisi metode hand sings dengan bersamaan dengan ketukan kaki kiri bergerak atau mengetuk mengikuti irama ketukan / beat minus one yang telah di konsep sebelumnya dengan bentuk melodi lagu yang telah di tulis pada score lagu bermain suling dalam memainkan nya antara tangan kanan dan kiri berbeda materi akan tetapi dimainkan secara bersamaan sebanyak 16 birama tadi dengan tanda birama / time signature 4/4 sehingga dalam praktiknya waktu yang mereka lalui dalam beat / ketukan itu 16 birama kali 4 beat dalam 1 biramanya maka jumlah 1 kali sesi putaran seandainya tempo kecepatan mengambil detik jam dalam 1 menit $=60$ detik berarti dapat memainkan dengan konsentrasi materi selama 1 menit 4 detik dan apabila dapat memainkannya dalam kondisi sempurna berarti tingkat konsentrasi terhadap penguasaan otak dalam mengolah perintah ke tangan kiri dan kanan berbeda yang sesuai dengan materi sehingga berjalan / dapat memisakan 3 konsertsasi 1 (tangan kiri ke alat musik recorder), 2 (tangan kanan ke dalam metode hand sings) 3 ( kaki kiri bergerak mengikuti beat musik) 4 (mata membaca score musik) dan 5 ( mendengarkan kesesuaian antara hasil bunyi alat musik dan back sound musik / mp3 minus one ) akan tetapi di point 5 di sarankan dapat mengahapalkan materi sebagai tujuan daya ingat sehingga antara organ tubuh.satu dengan yang lain dapat sinkron dalam memainkan materi yang di ujiankan dalam sesi putaran I.

- Di sesi putaran II hanya memofuskan pada penguasan letak nada alat musik recorder pada Tetra I yaitu c,d,e,f atau kita sebut form B / bagian B yang mana pada bagian tangan kanan kanan yang tadi berfungsi sebagai hang sings tadi berubah fungsi menutup lobang yang mana dalam konsep tata letak finger recorder lobang bagian atas tadi menutupi dengan jari sebelah kanan yaitu jari telunjuk,tengah dan manis dan pada form $b$ ini di tekankan pada penguasaan wilayah i octave tangga nada mayor c,d,e,f,g,a,b,c' dan cara peniupan yang di lakukan mulut dengan mengucapkan kalimat THU setiap not melodi lagu tadi sehingga bunyi yang di hasilkan. Di bagian form B ini apabila mereka memainkan dengan sempurna mereka sama memainkan dengan durasi waktu pada bagian Form A yaitu 1 menit 4 detik dikalikan 2 sesi sama dengan 128 beat sehingga jumlah waktu bentuk konsentrasi mereka menjadi 2 menit 8 detik.

- Di sesi III hanya konsentrasi pada teknik solfa pengucapan sol mi sa si pada tetra II yaitu 5,6,7,i / sol,la,si,do dengan suara/ bunyi yang di keluarkan oleh mulut mereka dengan konsentarsi pada ketepatan nada yang di keluarkan oleh bunyi alat musik recorder tadi dengan kontrol pitch nada agar dapat belajar mengingat picth nada supaya tidak sumbang atau nada fals dalam mengulangi lagi materi melodi lagu di form A dengan tetra II ,di sesi ini mereka juga memainkan hand sing sebagai penegas gerak tangan kanan bahwa apabila gerak hand sing naik maka nada tersebut juga naik akan tetapi bila gerak turun maka nada tersebut turun. Di sesi ini mereka sudah ketiga kalinya memainkan berarti jumlah waktu mereka lalui 1 menit : 4 detik ( 1 sesi / 64 beat di x 3 
berarti $=192$ beat dalam kurun waktu 3 x sesi atau sekitar 3 menit : 12 detik dalam tingkat konsentrasi penguasaan materi penguasaan pengucapan nada tinggi tersebut.

- Di sesi ke IV ini hanya konsentrasi pada teknik solfa pengucapan sol mi sa si, pada tetra I yaitu 1,2,3,4 / do,re,mi,fa sama dengan yang dilakukan pada sesi III akan tetapi mereka sudah berada pada form B.

- Di sesi ke IV ini berarti jumlah waktu mereka lalui 1 menit : 4 detik ( 1 sesi / 64 beat di x 4 berarti $=256$ beat dalam kurun waktu 4 x sesi atau sekitar 4 menit : 16 detik dalam tingkat konsentrasi penguasaan materi penguasaan pengucapan nada rendah tersebut.

Kesimpulan Langkah Materi dan sesi yang akan dimainkan

- I materi letak nada finger g,a,b,c' alat musik recoder dan hands sing.

- II materi letak nada finger c,d,e,f alat musik recorder .

- III materi teknik sol fa dan hand sing di range nada tinggi .

- IV materi teknik sol fa dan hand sing di range nada rendah.

\section{A. Simpulan}

\section{SIMPULAN DAN SARAN}

Dari hasil suatu pemikiran kita dalam memandang aktivitas seseorang naik sepeda motor tadi lah yang membuat saya berpikir dalam konteks bertanya pada diri sendiri hal ini ditegaskan dalam mata kuliah komunikasi seni hal ini termasuk dalam konteks komunikasi intrapersonal serta dapat saya simpulkan sesuatu yang dituangkan dalam gagsan itu sangat didasari dengan komunikasi intrapersonal seseorang dalam melangkah apa yang akan dipahami dari segala unsur yang akan dijadikan sebuah ide atau gagasan kita .

\section{B. Saran}

Mudahan dengan adanya pemikiran saya ini dapat dikembangkan dan dipergunakan oleh lapisan masyarakat sebagai media pembelajaran musik untuk landasan penguasaan olah wirasa wiraga dan wirama dalam suatu pembelajaran seni.

\section{DAFTAR RUJUKAN}

Jaeni, B. Wastap. (2014). Bahan Ajar Komunikasi Seni. Bandung : Pascasarjana ISBI

Rita Milyanti, T.Narawati, \& Endang Taryo. (2002). Buku Materi Pokok AKTA 8822 Strategi Pembelajaran Kesenian dan Keterampilan. Jakarta: PT. Gramedia.

M. Soeharto. (1980). Belajar Main Recorder. Jakarta: PT. Gramedia.

Sugianto, dkk. (2005). Kesenian untuk SMP Kelas VIII. Jakarta: PT. Erlangga.

Edi Sugiato \& Yuliani Nurani. (2005). Kemampuan Dasar Menulis, Jakarta ;Pusat Penerbitan Universitas Terbuka. 